\title{
El tratamiento con raloxifeno redujo la tasa de cáncer de mama en mujeres postmenopáusicas con niveles de estradiol elevados
}

Serum Estradiol Level and Risk of Breast Cancer During Treatment With Raloxifene. Cummings S R Duong T, Knyon E. JAMA 2002; 287: 216-220.

\section{Objetivo}

Probar la hipótesis de que el raloxifeno reduce más el riesgo de cáncer de mama, en mujeres con niveles altos de estradiol que en mujeres con muy bajo nivel de estradiol.

\section{Diseño}

Ensayo clínico aleatorizado controlado doble ciego con seguimiento de 5 años.

\section{Lugar}

Estudio multicéntrico en el ámbito comunitario de 25 países incluyendo EE.UU.

\section{Pacientes}

Un total de 7290 mujeres postmenopáusicas < de 80 años con diagnóstico de osteoporosis, quienes tenían un dosaje de concentración basal de estradiol medido en un laboratorio central utilizando un método sensible.

\section{Intervención}

Se aleatorizó a las pacientes para recibir $60 \mathrm{mg} / \mathrm{día}$ ó $120 \mathrm{mg} / \mathrm{día}$ de raloxifeno $(n=4843)$ ó placebo $(n=2447)$ durante 4 años.

\section{Medición de resultados principales}

Los nuevos casos histológicamente confirmados de cáncer de mama en los grupos de tratamiento y placebo, estratificado por niveles de estradiol.

\section{Resultados Principales}

En el grupo placebo las mujeres con niveles de estradiol superiores a $10 \mathrm{pmol} / \mathrm{L}(2.7 \mathrm{pg} / \mathrm{mL})$ tuvieron una tasa de cáncer de mama 6.8 veces superior ( $3 \%$ en 4 años, IC $95 \% 1.8 \%-4.1 \%$ ) a la observada en las mujeres con niveles indetectables de estradiol $(0.6 \%$ en 4 años, IC $95 \% 0 \%-1.1 \% p=0.05$ ). Las mujeres con niveles de estradiol $>10 \mathrm{pmol} / \mathrm{L}$ en el grupo de raloxifeno tuvieron una tasa de cáncer de mama de $76 \%$ (IC 95\% 53\%-88\%) más bajo que en las mujeres con niveles de estradiol $>10 \mathrm{pmol} / \mathrm{L}$ en el grupo placebo (reducción de riesgo absoluto* de 2.2\% (IC 95\% 1\%-3.5\% con un Número Necesario a Tratar para prevenir un cáncer de 45). Por el contrario, las mujeres con niveles indetectables de estradiol tuvieron un riesgo similar de cáncer de mama hubieran o no sido tratadas con raloxifeno (diferencia de riesgo $0.1 \%$, IC $95 \% 0.8 \%$ a $-0.6 \% p=N S$ ). En esta cohorte, la administración de raloxifeno durante 4 años, a las mujeres con niveles de estradiol superiores a $10 \mathrm{pmol} / \mathrm{L}$ pudo haber evitado un $47 \%$ de casos de cáncer de mama.

\section{Conclusiones}

La medición de los niveles de estradiol con un método sensible identificaría a las mujeres postmenopaúsicas con alto riesgo de cáncer de mama quienes se beneficiarían con el uso de raloxifeno. Si esto se confirmase, tratar a las mujeres con altos niveles de estradiol plasmático podría reducir la tasa de cáncer de mama en mujeres postmenopaúsicas.

Fuente de Financiamiento: Eli Lilly and $\mathrm{Co}$,Indianapolis, Ind.

\section{Comentario}

En el estudio MORE, el raloxifeno redujo el riesgo de desarrollar cáncer de mama invasivo en un $76 \%$ en mujeres postmenopaúsicas con receptores estrogénicos positivos, con 40 meses de uso ${ }^{1}$. La continuación de este ensayo clínico a 4 años sigue apoyando estos resultados.

Este estudio muestra una fuerte asociación del estradiol de las mujeres con el riesgo de cáncer de mama, y a su vez orienta a la población que se podría beneficiar con raloxifeno. Los niveles plasmáticos fueron medidos con técnicas muy sensibles que no se utilizan en la práctica clínica cotidiana, por lo cual la detección de grupos de alto riesgo sería dificultosa hasta poder estandarizar los métodos de diagnóstico de dosaje plasmático para utilizar de manera habitual. La mayor parte de la información que tenemos acerca del raloxifeno proviene del mismo ensayo clínico (MORE), el cual no fue diseñado para valorar de forma específica el beneficio del uso del fármaco en la prevención del cáncer de mama. Anteriormente fue demostrada la efectividad del uso de tamoxifeno en la prevención del cáncer de mama en mujeres de alto riesgo ${ }^{2}$. Actualmente se está realizando la comparación entre tamoxifeno y raloxifeno en el ensayo clínico STAR ${ }^{3}$.

Conclusión del comentario: Los datos de este estudio y otros nuevos con raloxifeno podrían, si ratifican los resultados demostrados en este ensayo clínico, desplazar el uso de tamoxifeno por raloxifeno para la prevención del cáncer de mama.

Dra. Marta I. Tützer [ Sección Climaterio, Servicio de Ginecología Hospital Italiano de Buenos Aires ] 